\title{
Zika-related knowledge, attitudes, and practices: Programmatic implications for Zika prevention in Honduras
}

Breakthrough RESEARCH

Follow this and additional works at: https://knowledgecommons.popcouncil.org/departments_sbsr-pgy

Part of the Health Communication Commons, and the Public Health Commons How does access to this work benefit you? Let us know!

\section{Recommended Citation}

Breakthrough RESEARCH. 2019. "Zika-related knowledge, attitudes, and practices: Programmatic implications for Zika prevention in Honduras," Programmatic Research Brief. Washington, DC: Population Council. 


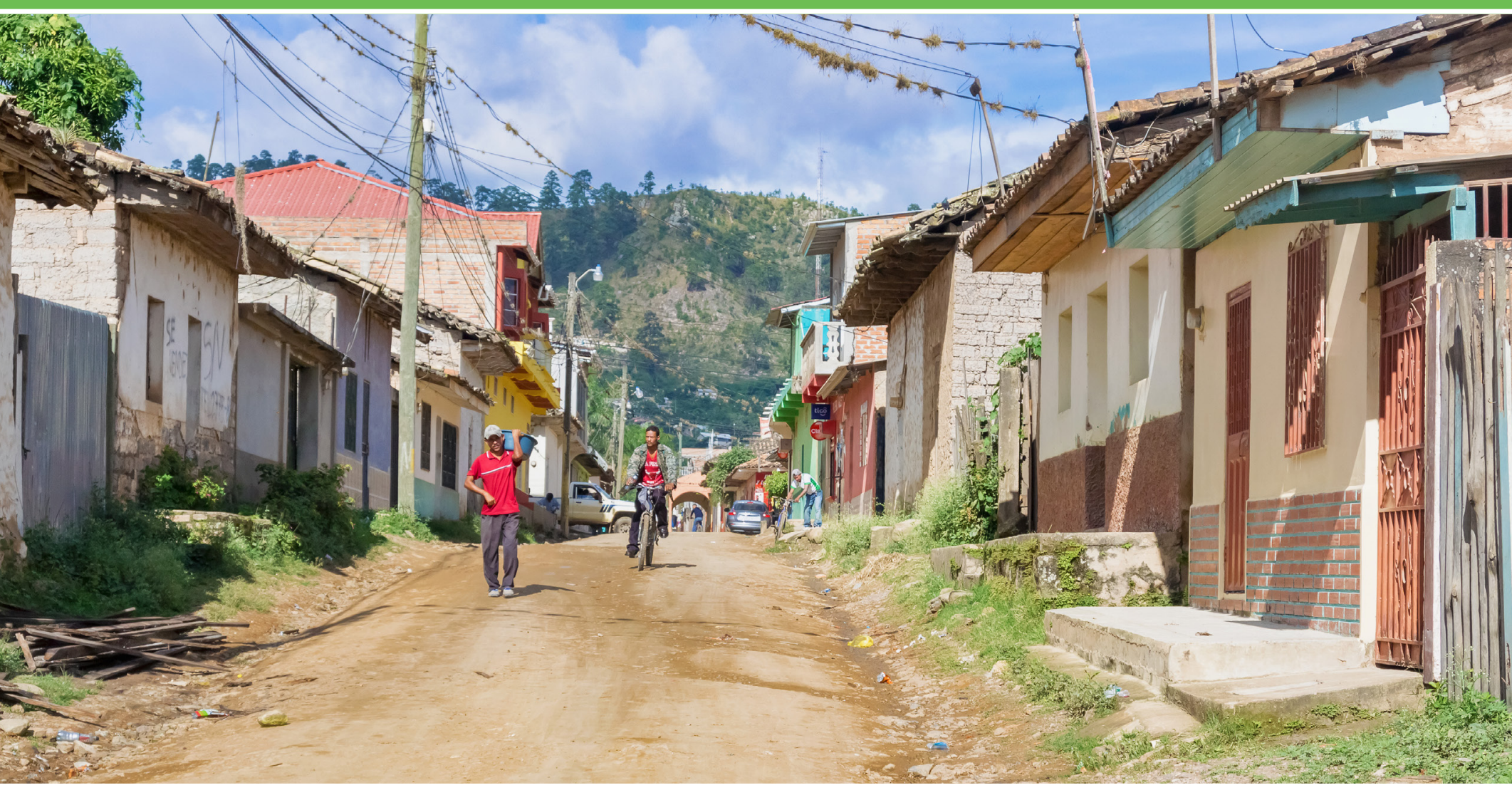

\section{Zika-Related Knowledge,} Attitudes, and Practices

This brief provides key insights for implementers of social and behavior change (SBC) activities for Zika prevention in Honduras. The insights are based on data from a representative sample of people living in select United States Agency for International Development (USAID) Zika program implementation communities and support an evidence-based approach for programming directed toward increasing the practice of prevention behaviors for Zika and other Aedes aegypti-transmitted viruses. The data indicate a need to: (1) narrow existing knowledge gaps related to the Zika virus, particularly its health consequences and effective preventive practices; and (2) communicate more specifically about preventive behaviors to enable effective action. 


\section{Background}

The first outbreak of Zika detected in the Americas occurred in 2015, with a spike in suspected congenital malformations and other neurological complications. ${ }^{1}$ In April 2016, the U.S. Department of State dedicated funding for the USAID Zika response, prioritizing prevention efforts and programming to minimize negative pregnancy outcomes in affected countries.

A key component of the USAID Zika response is SBC programming that aims to promote the uptake of effective prevention behaviors to reduce Zika transmission. Programs emphasize ensuring personal protection for pregnant women, engaging in high-risk communities to strengthen the resilience and responsiveness of in-country health systems, and improving women's demand for and access to antenatal care services. ${ }^{*}$

\section{Why Did We Collect Information on Knowledge, Attitudes, and Practices?}

Behavior change theories help us understand what enables and motivates people to act the way they do. ${ }^{4}$ The social-ecological model of behavior change highlights the importance of individual factors (such as knowledge, perceptions, and attitudes about a disease and how to prevent it), community-level factors (such as normative environment), and social and structural factors (such as access to resources and services) for understanding whether or not a person carries out a particular behavior. The extended parallel processing model highlights how a person's perception of risk associated with a disease, as well as their beliefs in the effectiveness of solutions and their own confidence to practice them, will influence whether people will take preventive action. ${ }^{4}$ These and other theories provide the groundwork to measure constructs that help SBC implementers make decisions about how best to influence behavior within target communities.

\section{How Was the Data Collected?}

In 2018, the Breakthrough RESEARCH project conducted cross-sectional household surveys in Guatemala, Honduras, El Salvador, and the Dominican Republic. The surveys assessed knowledge, attitudes, and practices among other factors related to Zika and other diseases transmitted by the Aedes aegypti mosquito. The multistage cluster random

* For more information visit www.usaid.gov/what-we-do/global-health/zika.

\section{WHY ZIKA MATTERS}

- Zika virus (ZIKV) is a communicable disease spread by Aedes aegypti mosquitoes, which also transmit other arboviruses including dengue and chikungunya. ${ }^{1}$

- ZIKV can also be transmitted through sexual intercourse and from pregnant mother to unborn child. ${ }^{1}$ ZIKV is known to cause neurological impacts, such as Congenital Zika Syndrome (CZS).

- Many people infected with ZIKV do not develop symptoms, leading to a lower perceived risk of infection. ${ }^{2}$ sample included men and women ages 18 to 49 living in USAID program implementation areas. In Honduras, the survey was carried out between August and October 2018 within implementation areas of five provinces: Francisco Morazán, Olancho, Valle, Choluteca, and El Paraiso. Interviews were conducted with 609 individuals, of which 36 percent were men and 64 percent women. Data were weighted by sociodemographic characteristics to reflect the population in the implementation areas.

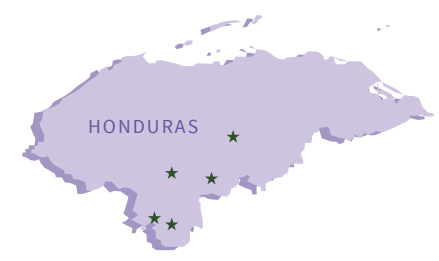

This study collected information in five main areas:

- Sociodemographics: Age, education, sex, household assets.

- Knowledge: Transmission, health effects, prevention for each disease.

- Attitudes: Perceptions of disease risk, effectiveness of prevention behaviors, feasibility of conducting prevention behaviors.

- Self-reported prevention practices: Behaviors to prevent mosquito bites and mosquito breeding in the last 30 days and last seven days.

- Observed practices: Observation of the use of secure lids for water storage containers in which mosquitoes are known to breed. 


\section{Programmatic Implications}

These insights for SBC programs are based on key findings from the surveys in Honduras.

1. Prevention programming should continue to include messages that highlight Zika's ability to be sexually transmitted, particularly among pregnant women and their partners, emphasizing the importance of condom use for transmission prevention during pregnancy.

2. Prevention programming and messages should emphasize the links between the Zika virus and birth defects, including CZS, especially among the male population, as it is a key differentiating factor between Zika and other arboviruses. For pregnant couples, having a healthy child may be a key motivator for prevention.

3. Prevention programming should prioritize behaviors that have greater evidence of effectiveness against Zika, particularly those for personal protection during pregnancy, which have lower perceived effectiveness than other less-effective behaviors.

4. Prevention programming should include messages that contain specific instructions for carrying out complex preventive behaviors.

5. Prevention messages delivered through interpersonal communication during household visits by vector control educators are a promising practice for promoting prevention behavior.

\section{Key Findings on Zika Knowledge}

\section{Awareness of Disease}

The overwhelming majority of people surveyed had heard about Zika, dengue, or chikungunya, and 90 percent of people had heard about all three diseases (see Table 1).

\begin{tabular}{|c|c|}
\hline DISEASE & $\begin{array}{c}\% \text { OF PEOPLE WHO HAD EVER } \\
\text { HEARD OF DISEASE }\end{array}$ \\
\hline Zika & 99\% \\
\hline Dengue & $95 \%$ \\
\hline Chikungunya & $91 \%$ \\
\hline
\end{tabular}

\section{Transmission and Health Effects}

By mosquitoes: Among those who had heard of each disease, nearly everyone knew that mosquitoes transmit Zika (92 percent), dengue (98 percent), and chikungunya (95 percent). About two out of every three people who were aware that mosquitoes transmit each virus knew that the mosquito can bite at any time of day or night ( 66 percent, 68 percent, 68 percent respectively).

Through sexual and vertical transmission: Only 11 percent of participants who had heard about Zika knew that it could be sexually transmitted, and 3 percent knew that it could be transmitted from mother to child during pregnancy.

Only 33 percent of Zika-aware participants identified birth defects as a health effect of the virus. Female participants were more aware that Zika causes birth defects than males (39 percent v. 27 percent, respectively, $p<0.01)^{\dagger}$

\section{Prevention Methods}

Among participants who were aware of Zika, 92 percent knew at least one method with a high potential to prevent the virus. ${ }^{\ddagger}$

+ Chi-square test for independence was used for all bivariate analyses.

‡ Effective behaviors: repellent use, clearing stagnant water, cleaning water storage containers, covering water storage containers, using larvicide, and using screens on windows and doors. 
The most commonly identified methods for reducing the risk of Zika were clearing stagnant water (65 percent), cleaning trash outside of the home to avoid mosquito breeding sites (66 percent), and scrubbing or cleaning water containers (60 percent).

Only 25 percent of participants identified covering containers, and 17 percent identified using larvicide as an effective prevention mechanism. Eleven percent identified repellent and 3 percent identified condoms as a Zika prevention mechanism.

\section{Key Findings on Attitudes About Zika}

\section{Perceived Risk of Zika, Dengue, and Chikungunya}

About half of study participants perceived themselves to be at low or no risk of Zika, dengue, and chikungunya, as presented in Figure 1 (51 percent, 49 percent, 50 percent respectively). Perceived risk of Zika was associated with wealth-37 percent of the poorest quintile considered themselves at high risk for contracting Zika, while only 12 percent of the richest quintiles considered themselves at high risk $(p<0.001)$.

FIGURE 1. RISK PERCEPTION BY DISEASE

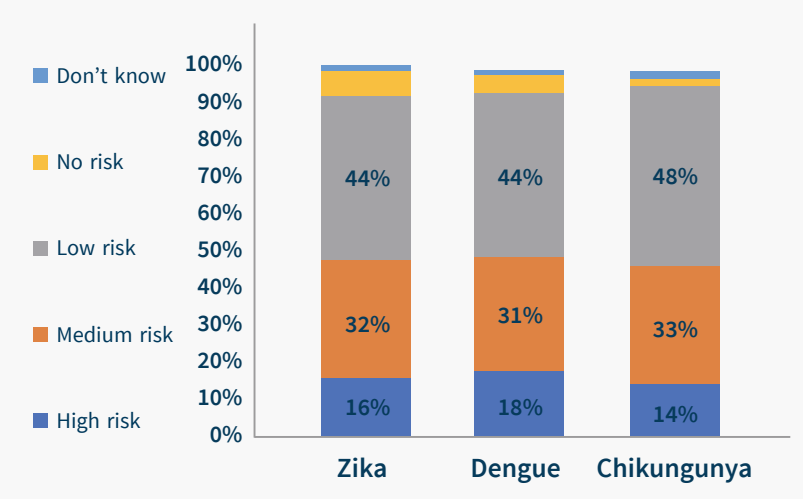

\section{Perceived Feasibility of Prevention Behaviors}

When asked about their perceptions of how easy it is to carry out certain prevention behaviors listed in Table 2, the majority of respondents do not report behaviors as being very easy. Less than 10 percent of study participants perceived the use of condoms in general and during pregnancy as very easy to do.

\begin{tabular}{l|c|}
$\begin{array}{l}\text { TABLE 2. PERCENTAGE OF PEOPLE REPORTING } \\
\text { PREVENTIVE BEHAVIOR TO BE VERY EASY }\end{array}$ \\
\hline BEHAVIOR & $\%$ \\
\hline Change water & $28 \%$ \\
\hline Use larvicide & $27 \%$ \\
\hline Remove water & $26 \%$ \\
\hline Clean water containers & $25 \%$ \\
\hline Cover water containers & $25 \%$ \\
\hline Use repellent & $25 \%$ \\
\hline Clear standing water & $23 \%$ \\
\hline Use condoms in general & $6 \%$ \\
\hline Use condoms during pregnancy & $6 \%$ \\
\hline
\end{tabular}

\section{Perceived Effectiveness of Prevention Behaviors}

When asked to rank prevention behaviors by how effective they are to prevent mosquito breeding and illnesses such as Zika, two-thirds of participants thought clearing trash outside the home was the most effective method, followed by clearing stagnant water (49 percent) and cleaning water storage containers (41 percent) (see Table 3).

Compared to men, significantly fewer women perceived using larvicide (11 percent v. 21 percent, $p<0.05$ ) or changing intentionally kept water ( 16 percent v. 24 percent, $p<0.01$ ) as among the top three most effective behaviors.

\section{Key Findings on Prevention Practices}

\section{Practices to Prevent the Sexual Transmission of Zika}

Although 15 percent of people surveyed reported using condoms during sex in the last 30 days, less than 1 percent of people surveyed reported using condoms to prevent Zika. 
TABLE 3. PERCENTAGE OF PEOPLE WHO PERCEIVE BEHAVIOR AS AMONG THE TOP THREE MOST EFFECTIVE

\begin{tabular}{l|c|}
\hline BEHAVIOR & $\%$ \\
\hline Clear trash outside the house & $62 \%$ \\
\hline Clear stagnant water & $49 \%$ \\
\hline Clean water storage containers & $41 \%$ \\
\hline Use mosquito spray (e.g. Raid ${ }^{\circledR}$ & $24 \%$ \\
\hline Change stagnant water & $20 \%$ \\
\hline Use repellent & $17 \%$ \\
\hline Use larvicide & $16 \%$ \\
\hline Cover water containers & $9 \%$ \\
\hline Use coils & $9 \%$ \\
\hline Use condoms & $6 \%$ \\
\hline Use bed nets & $4 \%$ \\
\hline Use screens on windows and doors & $4 \%$ \\
\hline
\end{tabular}

\section{Practices to Prevent Mosquito Bites and Mosquito Breeding}

Out of people interviewed:

- 78 percent of all participants said they had done something to prevent mosquito bites in the last $\mathbf{3 0}$ days, and 71 percent of participants carried out at least one behavior that had a high potential to be effective.

- 64 percent of all participants said they had done something to prevent mosquito bites in the last seven days, and 58 percent had carried out at least one behavior that had a high potential to be effective.

The most common responses to an open-ended question about prevention behaviors carried out in the last 30 days and the last seven days are presented in Figure 2. The most commonly reported behavior is cleaning trash/potential breeding sites, and the least common is wearing long-sleeve clothing. Behaviors with the greatest potential to be effective are marked with an asterisk.

Nearly one-quarter (22 percent) of people surveyed reported not participating in any type of mosquito prevention behavior in the past 30 days. Out of the people not doing anything for mosquito prevention, the most common reasons were being too busy ( 23 percent) and not being worried about mosquito bites (13 percent).

For individuals who reported not using repellent as a mosquito prevention behavior, the majority identified cost (34 percent) and lack of materials (22 percent) as barriers.

\section{FIGURE 2. PREVENTION BEHAVIORS IN LAST 30 AND LAST SEVEN DAYS}

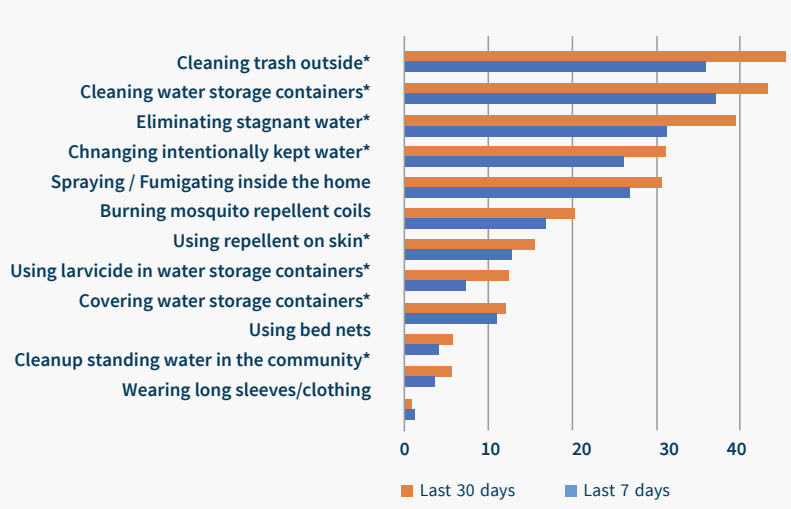

\section{Practices Concerning Water Storage Containers}

To understand how people in Honduras clean their water storage containers, we asked those who reported doing so in the last seven days to specify steps taken. Table 4 shows in rank order the actions reported to clean water storage containers. Over one-third of respondents (40 percent) mentioned applying detergent to the walls of the container, but only slightly more than half as many reported applying bleach (24 percent). About a quarter of people added bleach to water (25 percent), which is not an effective means of eliminating mosquito larvae or pupae. Fewer respondents mentioned scrubbing the walls of the container with a brush (18 percent), rinsing the container (17 percent), and emptying the container as a step to cleaning it (16 percent). Only 11 percent of respondents reported that they let cleaning ingredients act on the surface of the water storage container for a few minutes.

In addition to the survey, data were collected through observation of storage containers in participants' homes. Out of 609 respondents, 456 (75 percent) allowed surveyors to view their water storage containers. These included 480 wash basins (pilas) and 117 long-term water storage containers (commonly plastic drums). Surveyors observed containers for covers to assess the quality of the lids used. For a container to be effectively covered, lids must cover the container completely and fit tightly to avoid any gaps at 
any point in the circumference of the lid. If they are made from hard plastic, they must not be warped or allow water to pool on their surface. If they are made from a malleable material, they must not touch the surface of the water to form secondary breeding sites.

Overall, 10 percent of observed wash basins, and 18 percent of water storage containers were found to have mosquito

\section{TABLE 4. PERCENTAGE OF PEOPLE WHO CLEANED THEIR WATER STORAGE CONTAINER REPORTING ACTIONS INVOLVED IN CLEANING}

\begin{tabular}{l|c|}
\hline ACTIONS & $\%$ \\
\hline Apply detergent to walls of container & $40 \%$ \\
\hline Add bleach to the water & $25 \%$ \\
\hline Apply bleach to walls of container & $24 \%$ \\
\hline Scrub walls with brush & $18 \%$ \\
\hline Rinse container & $17 \%$ \\
\hline Empty the container & $16 \%$ \\
\hline Let ingredients act for a few minutes & $11 \%$ \\
\hline
\end{tabular}

larvae. No significant difference existed in the number of containers identified to have larvae regardless of whether the wash basins were effectively covered. On the other hand, long-term storage containers that were effectively covered were significantly less likely to have mosquito larvae at the time of observation than those not effectively covered (were not covered or had a cover that did not meet the effectiveness criteria). Two percent of effectively covered long-term storage containers had larvae, compared to 24 percent of containers that were not effectively covered $(p=.03)$. This effect holds true even when controlling for self-reported cleaning of containers in the last 30 days (see Table 5).

\section{TABLE 5. WATER STORAGE CONTAINERS WITH OBSERVED MOSQUITO LARVAE}

LONG-TERM STORAGE CONTAINERS

\begin{tabular}{|l|c|}
\hline Effectively Covered & $2 \%$ \\
\hline Not Effectively Covered & $24 \%$ \\
\hline
\end{tabular}

\section{Associations with Prevention Behaviors ${ }^{\S}$}

In Honduras, the most consistent factor associated with acting to prevent mosquito biting or breeding is knowledge of effective prevention behaviors. People with good knowledge about Zika-those who knew about eight different prevention behaviors-were 40 percentage points more likely to engage in effective behaviors than those who did not know any. Increased knowledge of effective prevention behaviors is significantly associated with greater self-reported use of covering water storage containers $(p<.001)$, clearing stagnant water $(p<.001)$, and cleaning water storage containers $(p<.001)$. Furthermore, knowledge that covering water storage containers prevents mosquito breeding is the only factor significantly associated with reportedly carrying out this behavior in the last 30 days.

Controlling for the level of knowledge, people who had been visited in their homes by someone who talked with them about how to prevent mosquitoes from breeding in and around their homes were 12 percentage points more likely to have reportedly cleared stagnant water and cleaned their water storage container in the last 30 days $(p=.01$ and $p=.006$ respectively).

A behavior's perceived effectiveness is significantly associated with clearing stagnant water and using mosquito repellent. People who thought clearing stagnant water was among the most effective prevention behavior were 10 percentage points more likely to have reportedly done so $(p=.02)$, and those who thought repellent use was among the most effective prevention behaviors were 24 percentage points more likely to have reportedly used repellents $(p<.001)$.

\section{Implications for Action}

Within the surveyed areas in Honduras, a large majority of people have heard about Zika, and almost all who have heard of it know that it can be transmitted by a mosquito. About two-thirds of people who know mosquitoes transmit Zika, dengue, and chikungunya also know that mosquitoes can bite at any time of day. On the other hand, knowledge of sexual transmission is very low, and fewer men than women are reportedly aware of the link between Zika during pregnancy and adverse pregnancy outcomes. Even though sexual transmission has been estimated to account for only 4 percent to 5 percent of overall Zika transmission, the implications of transmission during pregnancy are so severe that

$\S$ Results in this section were derived from logistic regression analyses. 
programs must continue to raise awareness of both sexual transmission of Zika and its potential health effects during pregnancy, particularly among pregnant women and their partners. ${ }^{5,6}$

People who were surveyed are already aware of most vector control prevention practices that can protect against mosquito breeding and diseases such as Zika. The one exception was knowledge about covering water storage containers. The percentage of people reporting to know personal protective behaviors against Zika, such as use of repellents and condoms, is particularly low. People are essentially unaware of condom use as a mechanism to protect against Zika. Additionally, highly effective prevention behaviors, such as covering water storage containers and using repellents on the skin, are practiced less frequently than less-effective behaviors such as burning coils or fumigating with spray.
Programs should continue to prioritize activities aimed at raising awareness of specific behaviors to prevent Zika, especially those personal protective behaviors that are particularly important during pregnancy. Messages should contain specific instructions on how to carry out complex preventive behaviors. ${ }^{7,8}$ Missed steps in vector control behaviors such as scrubbing water storage containers, letting cleaning agents act on container walls, and effectively covering containers used for long-term water storage are crucial for effectively eliminating mosquito breeding sites.

Lastly, home visits are a promising mechanism through which to engage at-risk populations to promote preventive practices. Stakeholders who conduct home visits may further incorporate promotion of personal protective behaviors to narrow the practice gap between vector control behaviors and personal protective behaviors. 


\section{References}

1 World Health Organization (WHO). 2016. Zika Strategic Response Plan. Geneva, Switzerland: WHO.

2 Haby, Michelle M. et al. 2018. "Prevalence of asymptomatic Zika virus infection: a systematic review," Bulletin of the World Health Organization 96: 402-413D.

3 Centers for Disease Control and Prevention (CDC). 2018. Congenital Zika Syndrome \& Other Birth Defects. Atlanta: CDC. Available from www.cdc.gov/pregnancy/ zika/testing-follow-up/zika-syndrome-birth-defects. html.

4 Health Communication Capacity Collaborative. 2016. Social and Behavior Change Communication for Emergency Preparedness Implementation Kit. Baltimore: Johns Hopkins University (JHU). Available from: http://healthcommcapacity.org/wp-content/ uploads/2017/01/SBCCforEP I-Kit.pdf.

5 Coelho, Flavio Codeco et al. 2016. "Higher incidence of Zika in adult women than adult men in Rio de Janeiro suggests a significant contribution of sexual transmission from men to women," International Journal of Infectious Diseases 51: 128-132.

6 Rao, Rashmi et al. 2017. "Zika risk and pregnancy in clinical practice: ongoing experience as the outbreak evolves," Obstetrics and Gynecology 129(6): 10981103.

7 Breakthrough ACTION+RESEARCH. 2018. Zika Prevention Behavior Matrix. Baltimore: JHU. Available from www.zikacommunicationnetwork.org/resources/ zika-prevention-behavior-matrix.

8 Breakthrough ACTION+RESEARCH. 2018. Technical Specification Content Guide for Behaviors With a High Potential to Prevent Zika. Baltimore: JHU. Available from www.zikacommunicationnetwork.org/resources/technical-specifications-content-guide-behaviors-high-potential-prevent-zika.

\section{Acknowledgements}

This programmatic research brief describes work led by Tulane University under Breakthrough RESEARCH in collaboration with TEPHINET in Honduras. The brief was edited and designed by Population Reference Bureau (PRB).

\section{Suggested citation:}

Breakthrough RESEARCH. 2019. "Zika-Related Knowledge, Attitudes, and Practices: Programmatic Implications for Zika Prevention in Honduras," Programmatic Research Brief. Washington, DC: Population Council.

Photo credits:

MarcPo, Getty Images

(c) The Population Council. All rights reserved

Breakthrough RESEARCH, Population Council

4301 Connecticut Ave., NW, Suite 280 | Washington, DC 20008 +12022379400 | breakthroughactionandresearch.org

BreakthroughRESEARCH@popcouncil.org

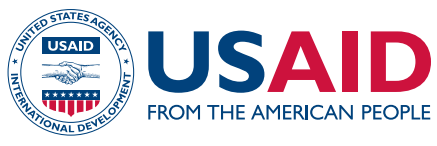

Breakthrough RESEARCH is made possible by the generous support of the American people through the United States Agency for International Development (USAID) under the terms of cooperative agreement no. AIDOAA-A-17-00018. The contents of this document are the sole responsibility of the Breakthrough RESEARCH and Population Council and do not necessarily reflect the views of USAID or the United States Government.

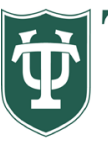

Tulane University

P

POPULATION COUNCIL

Ideas. Evidence. Impact.

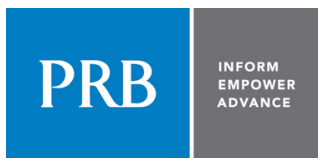

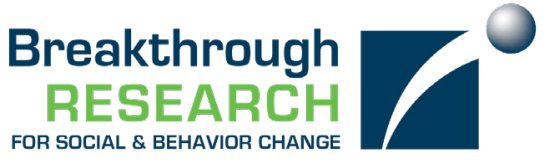

Breakthrough RESEARCH catalyzes social and behavior change (SBC) by conducting state-ofthe-art research and evaluation and promoting evidence-based solutions to improve health and development programs around the world. Breakthrough RESEARCH is a consortium led by the Population Council in partnership with Avenir Health, ideas42, Institute for Reproductive Health at Georgetown University, Population Reference Bureau, and Tulane University. 